\title{
EL PAPEL DE LA ORGANIZACIÓN AUTÓNOMA EN EL CAMBIO CULTURAL: ¿DETERMINADOS O RECONFIGURABLES POR LA ORGANIZACIÓN AUTÓNOMA?
}

\section{THE ROLE OF THE AUTONOMOUS ORGANIZATION IN CULTURAL CHANGE: DETERMINED OR RECONFIGURABLE BY THE AUTONOMOUS ORGANIZATION?}

\author{
Miguel Ángel Sobrado Cháves* \\ Juan José Rojas Herrera**
}

\begin{abstract}
RESUMEN
El objetivo general del presente artículo consiste en reflexionar acerca de las causas profundas que explican el atraso ancestral de las sociedades latinoamericanas y perfilar una estrategia de salida a dicha problemática. La metodología utilizada consistió en la revisión de un amplio material bibliográfico que permite constatar que el Estado fallido y la sociedad civil sumisa y diletante, que hoy distingue a la mayoría de los países latinoamericanos, constituyen las dos caras de un mismo círculo vicioso que reproduce el rezago económico y facilita la manipulación ideológica y política del clientelismo depredador. Para enfrentar tales obstáculos estructurales, se recomienda emprender un proceso de cambio que permita impulsar, en forma simultánea y coordinada, la reforma integral del Estado clientelista y la organización autónoma de la gente para que, al convertirse en sujeto colectivo, se movilice en pos de la construcción de soluciones innovadoras desde abajo.
\end{abstract}

PALABRAS CLAVE: AMÉRICA LATINA * SOCIEDAD CIVIL * ORGANIZACIÓN SOCIAL * POLÍTICA PÚBLICA * EMPRESA

** Pensionado de la Universidad Nacional, Costa Rica.

miguel.sobrado@gmail.com

** Departamento de Sociología Rural de la Universidad Autónoma de Chapingo, México.

rojashjj@gmail.com 


\begin{abstract}
The general objective of this article is to reflect on the causes that explain the ancestral backwardness of Latin American societies and provide an exit strategy to this problem. The methodology used consisted of reviewing extensive bibliographic material that shows that the failed state and the submissive and dilettante civil society, which today distinguishes most of the Latin American countries, constitute the two sides of the same vicious circle, which reproduces the economic lag and facilitates the ideological and political manipulation of predatory patronage. In order to face such structural obstacles, it is recommended to undertake a process of change that allows promoting, simultaneously and in coordination, the comprehensive reform of the client state and the autonomous organization of the people, so that when they become a collective subject, they mobilize in favor of building innovative solutions from below.
\end{abstract}

KEYWORDS: LATIN AMERICAN * CIVIL SOCIETY * SOCIAL ORGANIZATION * PUBLIC POLICY * ENTERPRISES

\section{INTRODUCCIÓN}

En la oferta institucional de los gobiernos latinoamericanos existen diversos programas y proyectos que apuntan a resolver síntomas de la pobreza con acciones puntuales de acuerdo a la visión que se tiene del problema. La mayoría se encuentran dirigidos a brindar asistencia por medio de la transferencia de recursos y otros programas se encuentran influidos por una visión más tecnocrática, con el fin de desarrollar capacidades.

Los primeros se orientan, sin hacer grandes distinciones, a imponer políticas y procesos a los "perdedores". Los segundos, cuando tienen experticia exigen requisitos y logran algunos resultados, pero solo sobre un sector reducido de la población. Unos y otros parten de visiones fragmentadas de la realidad a la que aplican soluciones estandarizadas. Los que ven "perdedores" ponen énfasis en una asistencia que rápidamente se transforma en asistencialismo. Los que aportan una visión más tecnocrática, escogen entre los que tienen mayor nivel educativo y motivación, a la población objetivo con la cual trabajar. A ambos, así como a otras visiones paralelas, les caracteriza el enfoque sobre las causas individuales de la pobreza y el tipo de soluciones instrumentales que requieren los "perdedores".
La pobreza, sin embargo, no es solo un fenómeno individual, sino que tiene un fuerte arraigo en el sistema económico, en la estructura del poder político y en la cultura de la sociedad. La cultura es el factor que ajusta y consolida el funcionamiento social ${ }^{1}$. Por esto, como se analizará más adelante, las soluciones que se implementen deben generar cambios en los grupos y sus productos deben facilitar la acumulación de respaldo proactivo desde las bases.

Ahora bien, si se enfoca el problema desde un plano más amplio, lo que diversas experiencias históricas alrededor del mundo parecen confirmar es que una de las condiciones imprescindibles para que una determinada sociedad alcance niveles aceptables de desarrollo económico y humano, está relacionada con la existencia paralela y simbiótica de una sociedad robusta y de un Estado fuerte que, en lugar de enfrascarse en una lucha de desgaste interminable $y$ sin vencedor posible, contribuyan mutuamente al impulso de un proyecto nacional de largo alcance.

1 Por cultura, en un sentido genérico, en este artículo se entiende al conjunto de valores y creencias compartidas por un determinado grupo social y que se manifiesta, en forma práctica, por medio de las conductas y los comportamientos habituales de dicho grupo social. 
Esta idea fue recuperada en el texto de la Recomendación sobre la Promoción de las Cooperativas, emitida por la Organización Internacional del Trabajo (OIT) en 2002, al señalar que: "Una sociedad equilibrada precisa la existencia de sectores públicos y privados fuertes $y$ de un fuerte sector cooperativo, mutualista $y$ de otras organizaciones sociales y no gubernamentales...".

Del mismo modo, en un trabajo más extenso, publicado en el año 2006, bajo el elocuente título de América Latina: Crisis del Estado clientelista y la construcción de Repúblicas Ciudadanas (Sobrado y Rojas, 2006), se plantea que los problemas del subdesarrollo latinoamericano se remontan a los orígenes $y$ se relacionan con el hecho de que en esta región del mundo, primero se configuró un Estado corporativo, excluyente de las poblaciones originarias, $y$ posteriormente, bajo el control y la tutela estatal, ha ido emergiendo, a oleadas intermitentes, la sociedad civil.

Más recientemente, el célebre y controvertido investigador Francis Fukuyama (2016), en su obra erudita: Los orígenes del orden político, además de confirmar el origen patrimonialista y corporativista del Estado latinoamericano, ha postulado que para que las sociedades humanas alcancen el equilibrio indispensable con el fin de propiciar las condiciones socio-económicas y políticas en las que florece el desarrollo humano, se necesita un Estado fuerte con límites legales y una sociedad civil sólida y organizada, que interactúen en forma positiva.

Con base en lo anterior, a manera de hipótesis, se estima que el Estado fallido y la sociedad civil sumisa y diletante, que hoy distingue a la mayoría de los países latinoamericanos, son las dos caras de un mismo círculo vicioso que reproduce el atraso económico y facilita la manipulación ideológica y política del clientelismo depredador. La gravedad de la coyuntura actual muestra a América Latina y buena parte del mundo asediados $y$ al borde del colapso ante la amenaza que representa la imparable reducción de puestos de trabajo provocada por la revolución tecnológica en curso, fenómeno que, a su vez, estimula el aumento de la pobreza y la delincuencia organizada. En las últimas cuatro décadas, el neoliberalismo y la globalización desfundaron económicamente al Estado latinoamericano, ahora es la narco violencia la que lo desmantela en el terreno político, al tiempo que mina su legitimidad legal. En este contexto, ni la política social instrumentada ni la militarización de las sociedades ocurrida en los últimos años, han sido suficientes para contener dicha amenaza. Antes, al contrario, el Estado daba muestras cada vez más evidentes de incapacidad e impotencia ante la magnitud de los problemas a resolver, en tanto que la sociedad civil se encuentra dividida $y$ paralizada, sin atinar a definir un rumbo seguro.

En consecuencia, frente a los enormes desafíos del mundo contemporáneo se aproxima a un dilema teórico-práctico fundamental, directamente relacionado con la definición del vehículo principal que serviría de apoyo para intentar salir de este impasse, el cual se formula en los siguientes términos: ¿Insistir en canalizar recursos públicos a los excluidos dejando intactos los mecanismos del control corporativo y clientelar existentes o promover la organización autónoma de la gente para que sea esta la que, al convertirse en sujeto colectivo, se movilice en pos de la construcción de soluciones innovadoras desde abajo?

En caso de que esta apuesta se incline a favor de la organización autónoma, los pueblos de América Latina tendrían, hacia el futuro inmediato, dos grandes tareas históricas que cumplir. Por una parte, se necesita recuperar al Estado del secuestro histórico que ha padecido por parte de las élites políticas y empresariales (Trocello, 2008). Secuestro que, en las últimas décadas, se ha tornado más burdo, al haberse subordinado a los intereses del gran capital, en el marco de las exigencias impuestas por el modelo neoliberal en boga, que ha provocado la exclusión social de amplios segmentos de la población trabajadora y la imposición de los bajos niveles de ingreso que estas perciben. En este sentido, una reforma profunda e integral del Estado clientelista es imperativa, si se aspira a tener un aparato estatal con compromiso social y que sea incluyente y garante de los intereses nacionales. 
Por otra parte, se requiere reactivar $y$ empoderar a la sociedad civil, utilizando los instrumentos de la política social para atender el enorme déficit que se padece en materia de capital social ${ }^{2}$ y comunidad cívica ${ }^{3}$. La construcción masiva de actores sociales proactivos $y$ organizados constituye un elemento indispensable para acabar con la desigualdad prevaleciente y para proponer seriamente la superación de los ancestrales lastres sociales y culturales.

Ambas tareas son simultáneas, pero el proceso, para ser efectivo, debe ir de abajo hacia arriba. Por ello, para limpiar al Estado de corruptos $y$ cleptócratas $y$ ponerlo a trabajar al servicio de un proyecto compartido de futuro $y$ de beneficio general, es necesario forjar la organización social de base comunitaria o territorial (Andersson y Richards, 2015). De acuerdo con lo anterior, la comunidad organizada está llamada a convertirse en el principal motor de cambio que, al desplegar su protagonismo, contribuye a crear una nueva realidad que permite impulsar la reforma del Estado, lo cual genera así una operación tenazas que atiende al proceso de cambio, tanto en la base social y económica como en la superestructura política y cultural.

En este artículo, con diferentes grados de profundidad y amplitud, se abordan las dos tareas señaladas, ordenando la exposición del tema en cuatro apartados. En el primero de ellos, se plantean algunos elementos del debate que se vive en las ciencias sociales respecto a la forma y grado en que la cultura

2 De acuerdo con Putnam, Leonardi y Nanetti (1994), "el capital social se refiere a las características de organización social, tales como la confianza, las normas y redes que pueden mejorar la eficiencia de la sociedad mediante la facilitación de las acciones coordinadas" (p. 212 ).

3 Al considerar a Putnam, Leonardi y Nanetti (1994) se asume que la comunidad cívica expresa una determinada situación de equilibrio social en la que se privilegian las necesidades públicas más que los fines personales $y$ en la que, por tanto, la ciudadanía "se caracteriza, ante todo, por una participación activa en los asuntos públicos" (p. 107) motivada no por un interés meramente altruista, sino por "un interés personal sensible frente a los intereses de los otros" (p. 108). política prevaleciente en una sociedad determinada, condiciona el comportamiento de sus ciudadanos en el procesamiento de los asuntos de interés general. El segundo, discute acerca del tipo de organización ciudadana que se requiere para impulsar la reconfiguración de los pueblos de América Latina en actores sociales con identidad y proyecto propio. El tercer apartado, está dedicado a exponer diversas experiencias de empoderamiento ciudadano ocurridas en diferentes continentes, así como, una propuesta metodológica para la alfabetización empresarial y cívica de amplias capas de población. En el cuarto y último se exponen las conclusiones provisionales derivadas del contenido del presente artículo.

\section{1) AJUSTE CULTURAL Y CAMBIO SOCIAL}

Es sabido que las relaciones de dominación raciales y de género operan, no solo desde el "exterior" sobre los grupos subordinados sino que se consolidan cuando estos internalizan la asimetría que se les impone. Como ejemplo de lo anterior, en los estudios realizados en los Estados Unidos en los años 60 con niños negros de entre 3 y 7 años (edades donde prevalece la influencia familiar en su formación), en los cuales se les mostraron dos muñecas, una negra y otra blanca, se les pidió a los niños que externaran sus cualidades positivas o negativas, con lo cual se obtuvieron una gran cantidad de respuestas en favor de la muñeca blanca y en detrimento de la negra. Este estudio fue repetido hace unos años en México con niños indígenas y los resultados divulgados en las redes sociales fueron aún más autodenigrantes. Otros estudios de género $y$ de clase social muestran también efectos auto discriminatorios, cuando no en el plano racional, en el ámbito emocional $y$ de comportamiento 4 .

De esta manera, la estructura social prevaleciente, ajusta internamente a los grupos

\footnotetext{
$4 \quad$ Una referencia más amplia y minuciosa a este tipo de estudios puede encontrarse en el libro de José Manuel Valenzuela Arce, El Color de las sombras: chicanos, identidad y racismo, publicado en 1998 por la editorial Plaza $y$ Valdés.
} 
para "facilitarles" su desempeño de acuerdo al rol que les toca jugar, sin tener que recurrir a mecanismos represivos "duros". Por eso, como señala Guillermo O'Donnel (1997), de todos los recursos de dominación, ya sean económicos, de información, de fuerza física o simbólicos, el más valioso en términos políticos es el ideológico porque naturaliza la desigualdad de la relación y produce la aceptación del dominado.

Empero, las dimensiones de clase, etnia o género son solo algunos de los aspectos de los que depende el acceso a las oportunidades; a los que hay que agregar las capacidades organizacionales y empresariales que asumen formas cada vez más líquidas o difusas. En su conjunto, estos factores definen los espacios de desempeño pero también los "techos" sociales de los grupos en el contexto cultural. Esto es particularmente relevante en un continente como el latinoamericano, que tiene la mayor desigualdad en la distribución del ingreso en el mundo, $y$ donde las dimensiones de etnia y clase tienden a combinarse con las de género o preferencia sexual. Todo ello en una época en la que rezagarse en el desempeño organizacional $y$ productivo equivale a perder perspectivas $y$ oportunidades en la escala social.

El origen sistémico de estas transformaciones, sin embargo, no es perceptible para los individuos, comunidades y grupos sociales que se enfrentan, de forma súbita, a la obsolescencia de su conocimiento $y$ capacidades, $y$ a una severa reducción de oportunidades. El fracaso es atribuido, por las élites en el poder, a ser un "perdedor", cuando no a la presencia de inmigrantes que ejercen competencia desleal. De esta suerte, la normalización de las asimetrías económicas, sociales y políticas, que robustecen las relaciones de poder, se produce sin aparente contradicción o resistencia por parte de los grupos subalternos.

\section{EL SUEÑO ANTICOLONIALISTA}

En el transcurso de la lucha anticolonialista desarrollada, principalmente en África, Asia y América Latina, durante las décadas de los 50 a los 70, Frantz Fanon (1963), siquiatra martiniqués, consciente de la dominación ideológica que habían logrado los europeos sobre sus colonias, decía que en el proceso de lucha anticolonial se forjaba el hombre nuevo. Añadía que cuando un colonizado mataba a un colonizador morían dos: un colonizador y un colonizado, y nacía un hombre libre que sería la base de ese hombre nuevo. Lamentablemente, aunque en el auge de la lucha se soñaba y se pensaba así, a medio siglo de distancia, se ha sido testigos de que dicha predicción no se cumplió. Las nuevas élites nativas que asumieron el control del gobierno reprodujeron las relaciones de poder autoritario y patrimonialista de los antiguos amos europeos. Con nuevos símbolos nacionalistas y revolucionarios, se mantuvo la cultura del poder centralizado y la subordinación de las grandes mayorías a ese poder omnímodo. De esta manera, se fraguó una pequeña élite de clase burocrática privilegiada, al tiempo que se mantuvieron en casi todos los antiguos países coloniales, los topes y las distancias sociales ${ }^{5}$.

En resumidas cuentas, las guerras de liberación nacional, si bien permitieron expulsar a los colonialistas, no dotaron a las comunidades de una organización ciudadana autónoma que se convirtiera en fundamento de la nueva articulación social desde las bases.

\section{EL AJUSTE EN LAS SOCIEDADES INDUSTRIALES}

En los tiempos que corren, el ajuste cultural no es una necesidad exclusiva de los llamados países en vías de desarrollo o emergentes, también lo es de aquellos que conforman el capitalismo central, ya que la revolución científico-tecnológica reclama cambios de fondo de todos los países.

A lo largo del siglo xIX y la primera parte del xx, el ajuste "automático" era relativamente suficiente para acceder $y$ mantenerse en las

$5 \quad$ Quizás como ningún otro autor, el polaco Ryszard Kapuscinski (1989 y 2000) ha documentado amplia y detalladamente este proceso de involución histórica en el continente africano en el que, entre otras calamidades, las élites dominantes poscoloniales han desatado verdaderas guerras de exterminio étnico-racial, que rayan en el genocidio $y$ los crímenes de lesa humanidad. 
estructuras productivas $y$ de clase de la primera fase industrial capitalista. El problema ahora es que en una época de rápidas transformaciones $y$ de diversos peligros de insostenibilidad ambiental, como la que se vive, no bastan las subordinaciones pasivas, sino que se requiere de una participación activa y de capacidades adaptativas crecientes.

En el pasado, mantener "ejércitos industriales de reserva” era funcional. En esta época, de economía globalizada, con producción automatizada y de robots, la situación es diferente, la mano de obra de baja calificación es excluida progresivamente $y$ se abre un abismo sociolaboral que erosiona y resquebraja el tejido social. En estas condiciones, el malestar se vuelve creciente $y$ las tendencias a la inestabilidad sistémica, tanto en el Norte como en el Sur, son cada vez más recurrentes.

\section{DESAGREGACIÓN DISCIPLINARIA Y UNIDAD DE LA} REALIDAD

Ante la creciente complejidad del mundo contemporáneo, la realidad puede fragmentarse por especialidades, pero solo para fines analíticos. La acción positiva sobre esta exige una visión integradora. Asimismo, tomando en cuenta que nadie se reproduce en forma aislada ni dispone de un manto de inmunidad ante el ambiente externo, se debe reconocer que en su cotidianidad, la gente vive dentro de un marco cultural y político históricamente determinado, donde el desarrollo y la pobreza se articulan en la práctica, por lo que solo en los confines de este marco puede actuar la política pública, lo cual genera condiciones y perspectivas que desencadenen las fuerzas latentes de la sociedad. Se trata de un contexto sinérgico donde los logros colectivos pueden estimular la participación, mitigar el aislamiento y la exclusión, y generar el respaldo necesario a las políticas implementadas.

Con base en el planteamiento anterior $y$ a fin de evitar dispersión $y$ disquisiciones teóricas interminables, vale la pena centrar el debate alrededor de las siguientes preguntas: ¿es inevitable el crecimiento de la desigualdad que alimenta el malestar y amenaza la paz social?, ¿por qué las ayudas para desempleo y la asistencia social, así como los cursos técnicos $y$ los programas de pymes, aunque ayudan, no resuelven el problema de fondo?, ¿por qué si el conocimiento y la práctica de capacitación organizacional requieren la autonomía del sujeto para obtener resultados en los proyectos sociales, esta no se permite a pesar de los costosos $y$ reiterados fracasos? En este análisis, se entiende que el obstáculo estructural de fondo se localiza en la organización institucional, la cual está concebida, articulada y condicionada por las formas ideológicas, por los patrones culturales y por las relaciones de poder vigentes. Este tema es complejo y llevaría a una reconceptualización del aparato público y sus funciones, la cual supera los alcances del presente artículo. Por tanto, se limitara a destacar tres elementos centrales que explican el problema:

1) Partir del supuesto de que la solución a los problemas de la gente debe venir desde arriba.

2) Predominio de una intencionalidad no declarada que pretende subordinar y cooptar con fines de clientelismo político a las nacientes organizaciones de base.

3) El sistema institucional se encuentra atomizado con funciones duplicadas $y$ descoordinadas, pues se carece de evaluación de programas y proyectos que orienten la inversión pública.

A continuación, se analizará el ámbito de influencia de cada uno de los aspectos antes señalados de una manera más detallada.

\section{VER LOS PROBLEMAS DESDE “ARRIBA"}

La visión desde arriba tiene su origen en una concepción elitista y discriminatoria que da por supuesto que la situación en que se encuentran las personas en situación de pobreza precisa una intervención externa, ya que se trata de individuos "perdedores" o que no pueden valerse por sí mismos y requieren asistencia.

A esta visión tutelar y paternalista de que los problemas sociales deben resolverse "de arriba-abajo", ya sea desde las agencias de desarrollo internacional o desde las instituciones públicas, 
se suma el pedagogismo de los técnicos que engarza con la visión institucional asistencial y el desconocimiento de la didáctica de educación de adultos y de las experiencias exitosas para el desarrollo local.

Innegablemente, existe un sector de pobreza extrema que por razones de edad o salud requiere servicios asistenciales, pero este sector es apenas el componente más vulnerable y necesitado. La mayor parte de quienes han caído en condición de pobreza, extrema o moderada, son producto de las transformaciones socioeconómicas, $y$ poseen condiciones que solo demandan oportunidades para salir adelante. Darles asistencia a estos grupos, en vez de resolver el problema, los transforma en personas pasivodependientes.

\section{LAS REDES DE PODER CLIENTELISTA}

Dentro del contexto institucional, además de la visión asistencial y paternalista, se encuentran empotradas, ideológicamente, las relaciones de poder político clientelistas que buscan lealtades y no eficiencia. Por ello, más allá de la forma y del discurso legitimador, el interés soterrado y primordial de la práctica clientelar no es otro que la subordinación y la lealtad incuestionable de los supuestos beneficiarios al patrón político en turno.

En razón de lo anterior, el diseño de las instituciones encargadas formalmente de promover la organización comunal, sindical o cooperativa, para generar capital social con los recursos públicos, se desvía e instrumentaliza con el objeto de consolidar el "liderazgo" de supuestos dirigentes, encargados de reforzar el tutelaje de las organizaciones de base. En este marco, la lucha por el control de las instituciones que manejan los recursos públicos, así como la cooptación de los líderes que monopolizan la representación social, se vuelve determinante para la refuncionalización de las relaciones de poder. De esta manera, en vez de gestar capital social y desarrollo económico, se construyen redes clientelares de dominación y dependencia, se crean condiciones favorables para que florezca la corrupción $y$, consecuentemente, se generaliza la ineficiencia administrativa.
PONER ORDEN EN LA DESCOORDINACIÓN INSTITUCIONAL Y REORIENTAR LAS POLÍTICAS PÚBLICAS

El diseño institucional actual requiere de un proceso de transformación progresivo que emane de la satisfacción de la gente y sea estimulado por los resultados alcanzados. Se necesita rediseñar el aparato institucional con políticas que motiven las capacidades de gestión y organización de la gente $y$ fomenten su participación en el desarrollo regional y territorial.

No se trata de una tarea simple, pues como se ha visto, el aparato público-administrativo obedece a otras dinámicas que no simpatizan con la autonomía; no obstante, poner orden en la descoordinación institucional, es posible en la medida que los recursos fluyan a través de un sistema descentralizado hacia la promoción y capacitación masiva de los trabajadores del campo y de la ciudad, asî como hacia el otorgamiento de eficientes servicios públicos de apoyo a las organizaciones ciudadanas, cuyos logros inmediatos pueden desatar sinergias que estimulen una mayor participación social en la solución de los problemas que les atañen.

En este mismo sentido, si se desea alcanzar el desarrollo y hacerlo con un tejido social fuerte, es preciso reorientar las políticas públicas hacia la generación de capacidades $y$ oportunidades. Por tal motivo, es necesario impulsar políticas públicas que estimulen las iniciativas de base, especialmente en el ámbito comunal y empresarial, que promuevan la sustentabilidad ambiental, la innovación local y la capacitación para propiciar encadenamientos entre actividades locales $y$ regionales, $y$, sobre todo, políticas que integren el quehacer de las organizaciones comunitarias y coadyuven a la formación y articulación de procesos centrípetos que impulsen el cambio cultural y amplíen la visión de futuro de la gente.

Fuera de los programas asistenciales dirigidos a personas que no pueden valerse por sî mismas por razones de edad, de enfermedad o por verse afectadas por algún desastre natural, no se necesitan programas y proyectos concebidos para ser ejecutados por las instituciones 
públicas llevando de la mano a los supuestos beneficiarios. Está demostrado por la experiencia internacional que este tipo de programas no genera iniciativa $y$ proactividad creativa, sino pasividad $y$ dependencia.

Cambiar las políticas públicas diseñadas para cooptar organizaciones o "ayudar" a la gente, por unas nuevas que capaciten e incentiven la organización autónoma y la iniciativa local y regional, no es una tarea de corto plazo, pero es preciso, cuanto antes, ponerlas en marcha a través de procesos acumulativos que empiecen a delinear una nueva tendencia en los términos anteriormente esbozados.

\section{2) ¿DETERMINADOS O RECONFIGURABLES POR LA ORGANIZACIÓN AUTÓNOMA?}

Derivado de lo señalado en el apartado anterior, es evidente que el cambio cultural debe reforzarse y cobrar impulso desde abajo, para lo cual se requiere de una sociedad civil activa y responsable. Sin embargo, los distintos contingentes que la constituyen no podrán ponerse en movimiento sin la transformación paulatina de los millones de parias sociales que hoy sobreviven de las migajas que obtienen de su participación subordinada y humillante en las redes del clientelismo político, en ciudadanos con plenos derechos, que no solamente sean capaces de vivir con decoro del producto de su trabajo sino que dispongan de los recursos suficientes para pagar sus impuestos $y$, en razón de ello, se sitúen en una posición de poder que les permita exigir un trato digno $y$ respetuoso de parte del Estado.

Colocarse en pie de igualdad con el Estado solo es posible si la sociedad civil está empoderada ${ }^{6}$. Dicho empoderamiento contiene un

6 Para Durston (2000), el empoderamiento "es un proceso selectivo consciente e intencionado que tiene como objetivo la igualación de oportunidades entre los sectores sociales. El criterio central es de transformación de sectores excluidos en actores, $y$ de nivelación hacia arriba de actores débiles" (p. 33). Pero, en la práctica, cada grupo social deberá protagonizar su propio empoderamiento, pues, en ninguna circunstancia, una entidad superior dará poder a otros. Por consiguiente, el empoderamiento, fuerte elemento de concientización social, pero solo adquiere capacidad transformadora cuando manifiesta su poder de convocatoria en la arena política. En efecto, la articulación de los intereses y las demandas de los ciudadanos dispersos a través de organizaciones profesionales y representativas, $y$ la movilización constante en pos de la defensa de tales intereses y demandas, es lo que convierte a las organizaciones sociales en instrumentos de cambio, con capacidad para responder a los desafíos de la época actual, tal como se intentará mostrar a continuación.

\section{LOS VIENTOS EN COLA QUE IMPULSAN EL CAMBIO}

Hoy más que nunca, la paulatina degradación ecológica, el deterioro progresivo del tejido social y las turbulencias políticas crecientes que amenazan la gestión y la gobernabilidad de las naciones, demandan aprender de las mejores prácticas y apropiarse del proyecto disruptivo y esperanzador enarbolado por diversas fuerzas sociales emergentes.

Empero, las nuevas formas de la acción colectiva no son antojadizas, sino que responden a las necesidades del medio ambiente $y$ de la gente, $y$ perfilan un nuevo tipo de organización económica y social, especialmente a partir de lo local. Se constituyen así en fuerzas de cambio que si encuentran condiciones favorables, esto es, políticas públicas estimulantes, crecerán por su propia dinámica e impulsarán, a su vez, nuevas transformaciones.

Por ello, lo que se trata es de estudiar y, sobre todo, promover estas nuevas formas de organización económica de tipo solidario con el medio ambiente y el tejido social, e impulsar condiciones a partir de lo regional y nacional para que estas fuerzas tomen protagonismo político creciente.

esencialmente, implica la creación, desarrollo y potencialización de las capacidades ciudadanas, empresariales $y$ técnicas de las personas y grupos sociales que estaban "dormidas" o no se utilizaban. Con base en lo anterior, se concluye que únicamente cuando un grupo social se ha auto empoderado, cuenta con capacidad real para incidir en las decisiones que le afectan. 
Del estudio, desde las universidades públicas, sobre la forma y el impacto que adquieren estas empresas y organizaciones puede irse aprendiendo y contribuir a acelerar la difusión y sistematización de las mejores prácticas. De manera especial, se recomienda enfatizar en el estudio de los siguientes fenómenos:

a) Experiencias de integración de saberes tradicionales con la ciencia moderna, que perfilan senderos prometedores en cuanto a la sostenibilidad del medio ambiente, el desarrollo local y el arraigo de la población rural. Estas experiencias son especialmente destacadas en el campo de la agroecología y configuran "cardúmenes" sociales con intereses propios y participación creciente cada vez más voluminosos que emergen como fuerza alternativa en el agro y en algunos centros urbanos.

b) Las formas de organización cooperativa surgidas como respuesta a diferentes situaciones, pero que son generadoras de capital social y articuladoras de los intereses ambientales, sociales y políticos de los habitantes de las comunidades.

c) Empresas privadas con responsabilidad social que, para competir con las transnacionales, por ejemplo, en el mercado turístico de cinco estrellas, desarrollan formas de disfrute del turismo amigables con el medio ambiente y la población del entorno?

d) Las organizaciones descentralizadas de alta tecnología que demandan sostenibilidad ambiental $y$ tejidos sociales estables.

Todo este tipo de organizaciones y empresas afloran como respuesta a las nuevas condiciones ecológicas, políticas y sociales, que estimulan la formación de poderes y fuerzas locales comprometidas abiertamente con un nuevo tipo de economía y de desarrollo endógeno.

$7 \quad$ Un ejemplo destacado de empresa privada con compromiso social y encadenamiento local, lo encontramos en el Hotel Punta Islita, ubicado en el Departamento de Guanacaste, Costa Rica, tal como lo ha documentado Bertheau (2010).

\section{ORGANIZACIÓN Y PODER}

La organización puede ser una disciplina más o una actividad exclusiva de las empresas y las instituciones, pero es mucho más que eso. La organización es un componente esencial para el desempeño en la vida social, en cuyos contornos se definen roles, se elaboran proyectos y se construyen expectativas de vida, al tiempo que se desarrollan capacidades individuales y colectivas.

El poder social cívico depende de la organización y esta, a su vez, de su grado de autonomía. Por eso, dado que los cambios cualitativos en los grupos humanos pasan por cambios en la cultura de la organización que los articula y representa, no se trata de impulsar la organización ciudadana en abstracto, sino aquella que garantice la práctica de la autonomía de gestión y la independencia frente a los diferentes grupos de interés. En este orden de ideas, el esquema de organización burocrática, creada de arriba abajo y por decisión o voluntad ajena a sus integrantes, lejos de ayudar al empoderamiento ciudadano, lo obstaculiza, al convertir a la naciente organización social en un ápice de un centro de poder externo que le prescribe o determina los límites de su acción colectiva. A los fines de la autogestión ciudadana tampoco abona el modelo de organización personalista o caudillista, en el que existe un líder carismático y todo poderoso, que se erige en representante inamovible e intermediario perpetuo entre la base social de la organización y los grupos externos de poder, ya sean instituciones públicas, partidos políticos, iglesias, agencias de desarrollo internacional u organizaciones no gubernamentales.

Si de empoderamiento ciudadano se trata, lo que se requiere es que aflore la organización autónoma, esto es, aquella generada por la gente para responder a sus necesidades $y$ prioridades, sin intervenciones ni imposiciones externas. Es este tipo de organización, en el que existen liderazgos colectivos y no solo individuales, el que genera condiciones para que broten como respuesta a las necesidades, las capacidades "dormidas" de los grupos, de tal modo que estos sean capaces de obtener resultados 
tangibles y consecuentemente generar nuevas expectativas y autoestima social.

Además, la organización autónoma se distingue por su fuerte enraizamiento territorial y por actuar en forma descentralizada. Por su capacidad para aprovechar el saber tradicional de los pueblos y lograr una síntesis enriquecedora con la tecnología moderna, al responder así a las necesidades del medio ambiente $y$ de la gente.

Como producto de lo antes señalado, la organización autónoma se convierte en un instrumento efectivo de los grupos y comunidades para actuar en la vida social y política, al tiempo que posibilita que los distintos grupos y sectores sociales puedan configurarse como sujetos colectivos con capacidad de resistencia ante los procesos de cooptación y manipulación clientelar, tanto del Estado como de otros actores políticos y sociales. En virtud de lo anterior, lo que se demanda de la organización social como instrumento de empoderamiento $y$ factor de cambio sistémico, es que a lo largo de su desarrollo sea capaz de cumplir con dos tareas estratégicas.

En primer lugar, que propicie el cambio cultural de los integrantes de su base social en la perspectiva aquí esbozada. Para lograr lo anterior, es preciso que la organización brinde servicios de capacitación y educación constantes para sus socios, de tal manera que se convierta en un espacio de formación cívica $y$ en una escuela humanista de experimentación e innovación técnica y social. Solo de este modo se logrará que los socios compartan una ética común, basada en los valores de autonomía, democracia, solidaridad, reciprocidad, equidad, transparencia y compromiso con la comunidad y el medio ambiente. Unos valores compartidos que operarán como mecanismos de integración $y$ de animación social y configurarán las señas de identidad colectiva de estas organizaciones autogestionarias.

En segundo lugar, que se conformen como empresas generadoras de empleo e ingreso dignos, con capacidad para garantizar la autonomía económica y el bienestar de sus socios. Dicho en términos más amplios, la misión de las organizaciones sociales autónomas consiste en impulsar el desarrollo local en un marco de sustentabilidad ambiental, lo cual implica mantener la cohesión interna de la comunidad, ofrecer empleo a las personas durante todo el año y evitar la migración.

HACIA UNA NUEVA FORMA DE ORGANIZACIÓN DE LA ECONOMÍA LOCAL

Con respecto a lo señalado, resulta indudable que no basta con impulsar la organización de la gente en las comunidades, es imprescindible también transformar las formas de producción e intercambio, aprovechando las mejores respuestas surgidas de la práctica. Por ello, ante el desastre social y ecológico provocado por la economía global capitalista, se requiere, cada vez con más urgencia, una nueva economía que opere con una racionalidad totalmente distinta a la mercantil-capitalista. Una economía que se distinga por dos características esenciales, en primer término, por su carácter reproductivo, es decir, que garantice la reproducción del hombre y la naturaleza en las mejores condiciones posibles de bienestar y de preservación de los ecosistemas. En segundo lugar, que no erosione el tejido social, lo que significa que debe cuidar que los efectos de la actividad económica no conduzcan al aumento de la pobreza, la marginación, la exclusión o la desigualdad social, sino al reforzamiento de las relaciones sociales. Por consiguiente, la economía, en general, y sus instrumentos, en particular, deben subordinarse al interés supremo de la sociedad, lo que significa que la economía, como creación humana, se pone al servicio del hombre y no el hombre al servicio de la economía.

Lo anterior, en ausencia de un Estado regulador y garante del interés general, solo puede lograrse a partir del ámbito local, de tal modo que la organización de las diferentes fases del ciclo económico: producción, distribución, intercambio, consumo y pos consumo, sean controladas progresivamente por los productores y consumidores directos, quienes comparten la proximidad territorial y el interés común.

Una economía como la anteriormente mencionada, en donde las cadenas de valor son gestionadas cada vez más local y regionalmente, 
y la producción se orienta hacia lo que la comunidad considera que es socialmente prioritario, en una primera etapa, solo puede materializarse en ámbitos territoriales definidos. En estas condiciones, al transformarse la comunidad en una poderosa institución económica y social, la interacción de los miembros de esta con otros individuos, grupos o áreas de interés situados fuera del entorno comunitario, en su mayor parte, ya no se realizará a nivel individual, sino a través de organizaciones o instituciones representativas.

Bajo esta lógica, el enraizamiento local y la autonomía de los sujetos colectivos se refuerzan mutuamente generando círculos virtuosos en los que el uso repetido de los actos de reciprocidad y el sostenimiento de las redes de interacción cívica, conducen a lo que Putnam, Leonardi y Nanetti (1994) denominan: densificación del tejido social, lo cual constituye una de las características que distinguen a una sociedad civil fuerte.

\section{IMPULSAR EL CAMBIO CON SENTIDO INTEGRAL}

Además de controlar los procesos productivos y las cadenas de comercialización y distribución de riqueza, es preciso transformar los diferentes aspectos de la vida cotidiana de las comunidades. Esto implica impulsar procesos paralelos de transformación en los planos ideológico, político, cultural y educativo.

La mutación profunda $y$ radical del sistema educativo vigente se vuelve imperativa, toda vez que este se encuentra orientado a disciplinar la fuerza de trabajo para que se inserte en relaciones laborales subordinadas. Ahora de lo que se trataría sería de impulsar un modelo educativo que además de enseñar a aprender, enseñar a hacer y enseñar a ser, enseñe a compartir, "entendido esto último como el aprender a vivir en común, bajo principios de cooperación, de respeto y de solidaridad" (Cadena, 2005, p. 36).

Desde el ámbito cultural a lo que se aspiraría es a que la comunidad fuese capaz de recuperar su historia $y$ tradiciones, rescatando los aspectos positivos de su cosmovisión para realizar una nueva síntesis, adaptada a las condiciones del mundo actual, de tal modo que logre afianzar una identidad cultural propia, ya sea campesina, indígena, urbana o semiurbana.

En el plano de lo político, el empoderamiento comunitario se pondría de manifiesto mediante dos procesos paralelos. Por una parte, a través del control de la acción disolvente $y$ de extracción del excedente económico que realizan los caciques, agiotistas e intermediarios de todo tipo, $y$, por la otra, mediante el acceso al poder local, que incluye desde las formas de organización tradicional como: los cabildos indígenas, las asambleas comunitarias o las mayordomías; pasando por las formas de organización formal, de carácter civil o agrario, tales como: los comisariados ejidales y comunales, las juntas de vecinos, los agentes o delegados municipales, los jueces auxiliares, los diversos comités de obras y servicios comunitarios o los clubes deportivos y culturales, hasta llegar al control de los gobiernos municipales.

\section{NO PERDER LA BATUTA DEL PROCESO DE CAMBIO}

En todo este proceso de transformación de la vida comunitaria, lo verdaderamente importante es que sea la comunidad la que defina las prioridades y marque el ritmo en la ejecución de las políticas de desarrollo local; pero, sin caer en un localismo chovinista y exacerbado, incapaz de incidir proactivamente en el entorno regional o nacional.

Este problema se subraya porque es probable que la transformación de los territorios bajo una lógica basada en la conducción de los poderes locales, no se pueda alcanzar exclusivamente con la intervención de las organizaciones comunitarias, pues se trata de una tarea compleja, de gran envergadura y de largo plazo. Por tal razón, la participación de otros agentes económicos, como las empresas públicas y privadas o las agencias de desarrollo internacional, puede ser deseable, siempre que la comunidad no pierda el liderazgo en la conducción del proceso de desarrollo.

Al establecer alianzas estratégicas con empresarios privados se debe evitar que estos alteren las dinámicas propias de las comunidades, actuando por cuenta propia y sin controles o restricciones, tal como ocurre en los marcos del sistema capitalista actual de libre mercado 
que no está sujeto a las políticas de los Estados nacionales, sino que, como ha podido observarse, responde a los exclusivos intereses de los empresarios privados que terminan convirtiéndose en depredadores de la naturaleza y en generadores de la enorme polarización social que distingue al mundo. Consecuentemente, la participación de cualquier agente económico externo a la comunidad, ya sea público o privado, debe servir para potenciar e incrementar los recursos existentes y no para saquearlos, destruirlos o degradarlos.

En síntesis, el cumplimiento cabal de esta tarea histórica solo es viable si las comunidades organizadas mantienen la conducción del proceso de desarrollo local en todas sus fases. Por tanto, no se trata de asumir una posición purista que niegue per se las alianzas temporales con empresarios privados $u$ otros agentes económicos, sino de garantizar que la participación de estos quede acotada a ciertas condiciones claramente definidas y plasmadas en un plan de desarrollo territorial ${ }^{8}$, aplicando el principio de que los intereses particulares no deben anteponerse al interés general, para evitar así la apropiación privada de los bienes públicos o de los recursos de uso común.

\section{CAMBIO CULTURAL LOCAL E INCIDENCIA EN LAS POLÍTICAS PÚBLICAS}

El cambio cultural en los grupos o colectivos sociales solo es perceptible en el largo plazo. Los valores éticos solo se entronizan y se convierten en hábito cotidiano de vida después de un largo período de maduración. Sin embargo, el proceso se puede acelerar si se actúa bajo un diseño predefinido donde la unidad del grupo y la práctica de la crítica y la autocrítica

$8 \quad$ Entre tales condiciones pueden mencionarse, a título de ejemplo, las siguientes: que la empresa privada genere riqueza y la reinvierta en la comunidad; que se encadene o contribuya a fortalecer los encadenamientos productivos ya existentes; que no se deslocalice en forma abrupta o repentina; que no destruya el medio ambiente, y que priorice la contratación de fuerza de trabajo local, apegándose a los parámetros del trabajo decente formulados por la Organización Internacional del Trabajo (OIT). se vuelven imperativas. De esta suerte, en una primera etapa, los logros de la organización comunitaria, en los ámbitos económico y social, serán los que esencialmente mantengan unido al grupo y no tanto los valores que aún se encontrarán en fase de asimilación por los integrantes del grupo. Así pues, atendiendo a las necesidades más acuciantes de los habitantes de la comunidad y realizando obras, que aunque sea en pequeña escala, sean suficientemente visibles, se logrará que los resultados obtenidos generen esperanza de cambio y respaldo creciente al proceso emprendido. De este modo, al poner orden y darle rumbo al desarrollo local, se conseguirá restablecer la confianza y reactivar la participación comunitaria.

Otro aspecto que no debe perderse de vista es que, una vez conquistado el espacio local por las comunidades organizadas, es indispensable cerrar el círculo de la transformación institucional del Estado nacional. La afirmación anterior, formulada en términos prácticos, implica comprender que la sobrevivencia a largo plazo de los territorios auto gestionados, solo será posible si las experiencias se comparten, si los logros se difunden y se utilizan como argumentos concretos $y$ tangibles, que deben influir sobre los "tomadores de decisión" al interior de los centros de poder, a fin de impulsar una modificación sustancial en el contenido y orientación de las políticas públicas de desarrollo a nivel regional. La presión hacia arriba debe ejercerse con el propósito de lograr que las políticas públicas adquieran un carácter más inclusivo de la gran diversidad local y regional, basadas en el respeto a la pluralidad de formas de organización y de hacer economía, de acuerdo con las condiciones que impongan los contextos locales y regionales, $y$ no obedeciendo a lineamientos centralistas, burocráticos y clientelistas.

Por tanto, lo que se requiere es una reforma integral del Estado que, en el ámbito de este análisis, admita descentralizar sus funciones, transfiriendo competencias a los estados $y$ municipios, $y$ que de manera especial, deje en manos de las comunidades organizadas, la ejecución final de la política social, lo cual permitiría una redistribución de activos que 
vendría a robustecer la autonomía regional y a imprimirle a la política social un contenido netamente popular.

En suma, solo cuando la organización de base comunitaria hubiese alcanzado un grado de profesionalismo tal que le permitiera cumplir con creces su papel como agente protagónico del desarrollo local de su comunidad, estaría, al mismo tiempo, en condiciones de hacer que se fortaleciera y consolidara una cultura cooperativa, autogestionaria y solidaria que ensancharía en forma significativa los techos aspiracionales de los participantes en el proceso de cambio. Cuando todo esto ocurra, ya no habrá espacio para la autodenigración cultural, ni para la domesticación clientelista: el pueblo se habrá liberado a sí mismo. El maleficio de la determinación histórica del atraso cultural se habrá roto $y$ los sectores populares se habrán reconfigurado como actores sociales mediante la organización autónoma.

\section{3) EXPERIENCIAS DESTACADAS DE EMPODERAMIENTO CIUDADANO E INSTRUMENTOS METODOLÓGICOS PARA IMPULSAR LA ORGANIZACIÓN AUTÓNOMA}

Experiencias exitosas de empoderamiento ciudadano en América Latina, África y Europa, que se pueden consultar, entre otras fuentes, en el libro: Un futuro para los excluidos, coordinado por Carmen y Sobrado (2004), han mostrado caminos alentadores de superación y ajuste cultural basados en las iniciativas y la autonomía de los grupos. Tales experiencias han estado orientadas por el paradigma de la Actividad $\mathrm{Ob}$ jetivada elaborada inicialmente por Lev Vygotsky (1978 y 1995), y continuada de manera creativa por Aleksei Leontiev (1981), la cual postula que el cambio del modo de pensar de los grupos, se inicia con mudanzas en su actividad productiva al enfrentarse a un nuevo objeto organizacional, que ajusta $y$ dinamiza la cultura grupal ${ }^{9}$.

$9 \quad$ Una excelente síntesis, desde la perspectiva de la psicología social, puede verse en el artículo de Roth y Lee: "Vigotsky's neglected legacy: Cultural historical activity theory", publicado en 2007, en Review of Educational Research.
Atendiendo a este mismo principio, pero en el contexto de lo que posteriormente dio origen a la Metodología de Capacitación Masiva (МСм) y a su instrumento metodológico más elaborado: el Laboratorio Organizacional ${ }^{10}$, se ha confirmado que no son los instructores o expertos, sino la empresa de organización creada por el grupo grande la que transforma su cultura organizacional. En otras palabras, el grupo logra organizarse como consecuencia de tener todas las herramientas $y$ equipos necesarios para actuar autónomamente, en plena libertad $y$ dentro del marco legal. En este proceso, los grupos, al atender sus necesidades, desarrollan habilidades $y$ destrezas que los capacitan para superarse económica y cívicamente, habilitándose para resquebrajar los techos sociales que históricamente limitaron sus expectativas y potencialidades. Se trata de una actividad real donde los grupos descubren y ponen en marcha sus capacidades latentes. Un verdadero proceso de resurrección social por medio del que se capacitan en el manejo de las formas predominantes de organización para la vida económica y social, al tiempo que se estimula la transformación cultural.

Empresas asociativas como Hondupalma y Coapalma en Honduras, o como Coopesilencio en Costa Rica, surgidas del Laboratorio Organizacional, son un ejemplo vivo del potencial desarrollado por obreros agrícolas de muy bajo nivel educativo, en la construcción de grandes empresas de miles de hectáreas, en los años 70 del siglo pasado. Más recientemente, la experiencia de la ONG SERITI en Suráfrica con sus Programas de Trabajo Comunitario (PTC) en 49 cantones de seis provincias, atraen a los marginados alrededor de sus problemas comunales más urgentes, como primer paso para generar fuentes de ingreso y empleo mediante un esfuerzo colectivo.

10 La metodología de Capacitación Masiva fue creada $y$ desarrollada por el sociólogo brasileño Clodomir Santos de Morais, a principios de la década de los años 60. Ha sido aplicada con éxito en diferentes países de África, Europa y América Latina en las últimas cinco décadas. Un resumen de sus fundamentos epistemológicos, así como de los principales elementos de su ingeniería social, puede consultarse en el anexo del libro de Sobrado y Rojas (2006). 
Las comunidades rurales una vez organizadas se ponen en movimiento para atender sus problemas comunes, preservar las formas de sobrevivencia cotidianas, mejorar sus condiciones de vida $y$ obtener un ingreso pequeño pero fijo. De paso, se apoderan de la gestión ciudadana democratizando y fortaleciendo el desempeño de los municipios ${ }^{11}$.

Más allá del Laboratorio Organizacional moraiseano, pero siguiendo el principio de la autonomía de las comunidades, se encuentra la experiencia organizacional en el campo de la salud, conocida como Hospital sin Paredes, desarrollada por el Dr. Juan Guillermo Ortiz Guier en cinco cantones de la meseta central occidental de Costa Rica, en la década de los 70 del siglo xx. Una experiencia destacada en el ámbito nacional y mundial por su efecto en la reducción de la mortalidad materna infantil y por elevar los índices de salud y las condiciones de vida de la población incluida en la cobertura del programa, en poco tiempo y con bajos niveles de inversión.

Esta experiencia está recuperada en el libro de Juan Guillermo Ortiz Guier, titulado: Epopeya Ramonense: parte de la Odisea de San Ramón, publicado en el 2001, en el cual se subraya que la consigna del Programa Hospital Sin Paredes (PHSP) era: Salud para todos: El hospital va a la gente no la gente al hospital. De este modo, se garantizaba que los beneficiarios sintieran como suyo el proyecto y que fuese la propia comunidad, a través de los 160 puestos de salud que fueron montados, la que tuviera el poder en sus manos, acabando así con los intereses creados y la centralización del poder en las ciudades.

Al ser la salud una necesidad de las comunidades que depende de los servicios y condiciones ambientales, la participación ciudadana

11 A efecto de profundizar en el conocimiento de esta experiencia puede consultarse la página web: $w w w$. seriti.org.za. Para tener una visión más completa acerca de las experiencias iniciales de aplicación de la Metodología de Capacitación Masiva en Suráfrica, como estrategia para mitigar la violencia interétnica y fortalecer el tejido social, puede verse el trabajo de Langa (2015) y el de Andersson $y$ Richards (2015). se produce de manera natural, espontánea y desinteresada, de tal manera que, a pesar del mínimo apoyo gubernamental, el sistema de voluntariado establecido y el trabajo colectivo, permiten sacar adelante las iniciativas populares. En este sentido, la clave del éxito estuvo en lograr que todos los integrantes de las comunidades participaran a partir de sus posibilidades: hombres, mujeres, niños, viejos, minusválidos, etc., existiendo oportunidades de participación $y$ de capacitación técnica para cualquier persona que se involucrara en la práctica concreta. Lo que por encima de todo se procuraba era no desperdiciar ninguna energía social, sino activarla y movilizarla en la dirección correcta.

De este modo, se formaron decenas de enfermeras de las propias comunidades, imbuidas de una alta motivación y mística de servicio, quienes caminaban largas distancias de comunidad en comunidad e iban casa por casa, diagnosticando y dando seguimiento a los enfermos, convenciéndolos de que participaran en las campañas de salud, que se dejaran vacunar, asimismo, que mejoraran sus condiciones y hábitos de higiene, lo que aunado a la construcción de acueductos, letrinas y caminos, generó las condiciones que hicieron posible que la población lograra adquirir y mantener la inmunidad en su territorio. Con el paso del tiempo, este conjunto de prácticas sociales, al arraigarse en la mente de los beneficiarios, derivó en la adopción de una cultura comunitaria de prevención en materia de salud pública.

Como puede apreciarse, esta experiencia se apoyó en las propias fuerzas y recursos de la comunidad, no dependió del exterior ni se quedó esperando soluciones "que cayeran del cielo", por lo que se trató de una construcción social vital, alejada de intereses políticos de grupo o partido, en la que la gente actuó con autonomía plena. De esta manera, se creó también un conocimiento local que recuperó el ya existente, actualizándolo y desarrollándolo al confrontarlo con los nuevos desafíos de la época actual, con lo que la tecnología médica se adaptó al contexto local.

Finalmente, se estima conveniente agregar que, también en Asia ha habido experiencias de autogestión sobresalientes, entre las que 
se pueden mencionar, por un parte, a la China post Mao, que mostró un desarrollo y participación comunal intenso a raíz del proceso iniciado por la revolución agraria de 1978, así como, la descentralización y las nuevas dinámicas políticas que la acompañaron (Xiaobo, 2010). Por otra parte, en Vietnam, es reconocido que el triunfo en la guerra contra los franceses primero y los norteamericanos después, a pesar de la descomunal desventaja económica y militar entre los contendientes, se sustentó en la activa participación de las comunidades, tanto en el planeamiento como en la ejecución de las operaciones de guerra, dando lugar a propuestas innovadoras de acción colectiva de masas que se expresaban en consignas, tales como: "la guerra de todo el pueblo" y "la primacía de la política sobre las acciones de guerra" (Burchet, 1969). Estos dos casos resultan además paradigmáticos porque en ellos se desataron significativos procesos de empoderamiento organizacional que provocaron cambios profundos en la cultura campesina tradicional.

\section{4) REFLEXIONES FINALES}

Como se ha visto a lo largo del presente artículo, la estructura social desarrolla mecanismos $y$ valores que una vez internalizados por los grupos e individuos, facilitan su subordinación y ajuste al sistema de dominación prevaleciente. En este sentido, el campo de la cultura política se convierte en el escenario de la lucha ideológica por imponer significaciones colectivas y construir en el imaginario social la creencia de la legitimidad e inevitabilidad de la dominación, ya sea esta de origen mítico o enteramente terrenal. En virtud de lo anterior, resulta evidente que la dominación política $y$ social se vuelve estable y duradera en el momento en que logra combinar, en la proporción necesaria, tanto el componente objetivo e instrumental con los ingredientes subjetivos $y$ culturales de esta.

Vista desde esta perspectiva, la pobreza no es solo algo que se refleja en el ingreso, sino que tiene su arraigo en la cultura prevaleciente, reforzada por las políticas sociales asistenciales, que ve a las personas en condición de pobreza como "perdedores" a los cuales hay que ayudar desde arriba, lo cual promueve de esta forma su pasividad $y$ dependencia. Lo antes dicho significa que la visión epistemológica y la estructura de poder prevaleciente entre los encargados del diseño y la ejecución de la política social, impide que se generen programas encaminados a impulsar el empoderamiento ciudadano.

De este modo, el enfoque asistencial no solo empotra en la pobreza y refuerza la dominación social y cultural, sino que esto se realiza a contrapelo del conocimiento práctico, confirmado por la teoría de la actividad objetivada y de las experiencias de la andragogía o educación de personas adultas, que definen a la autonomía de estas, como un requisito para el éxito de la capacitación y el aprendizaje. Por consiguiente, la superación de la pobreza no se puede realizar solo con transferencias, sino que debe darse dentro de un proceso organizacional de actividades que transformen la cultura.

La organización autónoma de las personas excluidas y la capacitación masiva han sido los pivotes de la innovación y "resurrección", o sea, del despertar de capacidades subyacentes, que han dado origen a las mejores prácticas, antes citadas, mediante las que se han apoderado a grupos y comunidades en diferentes latitudes y contextos políticos y religiosos. Sin embargo, se considera importante precisar que, sin duda, el papel de la educación resulta crucial porque permite la formación de capital humano, pero es la capacitación en organización cívica y empresarial la que genera poder real y contribuye a la formación del capital social necesario para el desarrollo sostenible.

Esto es así debido a que únicamente en las profundidades de la dinámica organizacional, en condiciones de autonomía, es que los grupos y comunidades experimentan dos procesos fundamentales que los habilitan para un mejor desempeño en la vida económica y política de sus sociedades: en primer lugar, se produce un proceso de rompimiento con los modelos tradicionales de organización social y se inicia la adopción de una nueva forma de organización con división social del trabajo altamente participativa y democrática $y$, en segundo lugar, se realiza un fuerte cuestionamiento teórico y actitudinal de los valores prevalecientes y se da 
curso a la gestación de una nueva cultura humanista, solidaria y de autogestión, construida desde abajo. De esta manera, lo que se produce no es solo un cambio técnico-organizativo, sino una verdadera transformación cultural que reemplaza la vieja cultura clientelista, asistencialista $y$ tutelar, $y$ que posibilita que los grupos participantes se apoderen de su suerte, emprendiendo caminos $y$ proyectos que les permiten romper progresivamente los techos sociales a los que han estado sometidos.

Por todo lo indicado anteriormente, si se desea acabar con la autodenigración y la falta de autoestima social que fortalece y consolida los mecanismos de dominación cultural de los pueblos, es preciso partir de este paradigma que consiste en cambiar las condiciones de reproducción económica y social de los sectores marginados, al tiempo que se crea y recrea una nueva cultura popular y democrática. Si se observa con detenimiento, se descubrirá que, en el fondo, se trata de un recurso subyacente en toda comunidad humana y que lo único que se requiere es confiar en el potencial de las comunidades y grupos organizados, en su capacidad de gestión, en su creatividad y en su conocimiento o sabiduría ancestral y no suponer que las soluciones a los grandes problemas sociales deben venir siempre de arriba-abajo.

En consecuencia, la capacidad o energía social indispensable para promover la transformación cultural solo puede generarse desde "abajo", en condiciones de autonomía y respondiendo a las necesidades reales de los grupos y las comunidades, lo que permitirá que el ajuste cultural necesario sea obra de la gente. Esto desde luego, requiere de políticas públicas que estimulen la descentralización y el desarrollo incluyente, que transfieran atribuciones que empoderen y capaciten en organización y gestión a las comunidades y grupos organizados. Esas políticas se darán, no solo por el interés de los políticos con visión, sino por la participación, acción y peso de las organizaciones en la vida regional y nacional.

Pero, a su vez, es preciso reconocer que la transformación completa e integral debe complementarse desde arriba, mediante una reforma integral del Estado que permita su rescate del secuestro histórico al que ha estado sometido por parte de una minoría privilegiada. Dicho rescate no solo es prioritario sino que asume un carácter estratégico y trascendental, ya que si ello no ocurre, entonces no se podrá impulsar ningún cambio verdadero.

En definitiva, para acabar con la república de fachada ficticia y simulada que hoy se tiene y empezar a construir una república ciudadana, democrática y soberana, es necesario transformar al actual Estado clientelista y paternalista en una empresa de todos y todas, sujeta al control ciudadano y orientada al bien común. La aparente neutralidad que frente a las fuerzas del mercado se le exige al Estado es inadmisible, como lo es también consentir que no asuma su responsabilidad pública y social, ya que, en esencia, su misión o razón de ser no es otra que velar por el bienestar de la ciudadanía y salvaguardar la soberanía nacional.

Evidentemente, el rescate del Estado no podrá consumarse en un solo acto, sino a través de un proceso gradual $y$ altamente participativo, por lo que debe llevarse a cabo mediante métodos pacíficos ajustados a la democracia participativa. Para cumplir con dicho propósito, se recomienda la puesta en marcha de una "operación tenazas", es decir, el movimiento simultaneo y coordinado desde abajo y desde arriba de las fuerzas progresistas y promotoras del cambio. Bajo esta perspectiva, lo que se trata es de combinar y complementar los procesos de construcción de la autogestión local $y$ comunitaria a nivel territorial $y$ regional con la reforma y democratización del Estado y la vida política, pues solo de esta manera se podrá empezar a sustituir el tradicional divorcio entre Estado y sociedad civil por la acción sincrónica, concurrente y responsable de ambos actores, en torno a un proyecto compartido de futuro.

En suma, lo que se requiere para superar la autodenigración colectiva que les impide actuar como actores sociales con intereses y demandas propias, $y$ los mantiene en la postración y la pasividad, es un cambio a partir de nuevas prácticas sociales y culturales impulsadas por las organizaciones incluyentes $y$ una nueva política social orientada al desarrollo de capacidades empresariales y ciudadanas, 
todo lo cual deberá generarse a partir de los logros concretos que se vayan acumulando en la práctica social organizada.

De esta manera, si se admite que el punto de partida del proceso de cambio no es otro que el de la autonomía de las comunidades y grupos, entonces se tendría que asumir que, tal como sucede en el ámbito individual, no se puede aprender a manejar un vehículo si al aprendiz no se le permite asumir el control de este, tampoco se podrá capacitar en temas de organización a los grupos o a las comunidades con proyectos hechos desde un escritorio y llevando a las comunidades de la mano, como si fueran menores de edad. Actualmente, existen en el mundo diversas metodologías de capacitación en organización autónoma que pueden emplearse para acelerar los procesos de empoderamiento ciudadano, lo único que hace falta es voluntad política para reconocer que el desarrollo de los territorios es responsabilidad directa e inmediata de sus pobladores y que lo más conveniente para todos y todas, es dejarlos en sus manos.

En este mismo sentido, se considera que la degradación irrefrenable del medio ambiente, el deterioro progresivo del tejido social y las turbulencias políticas crecientes que amenazan la legitimidad $y$ la gobernabilidad de los estados nacionales, demandan aprender de las mejores prácticas de autogestión comunitaria que se han desarrollado tanto a nivel nacional como internacional, tarea en la que las universidades pueden hacer una valiosa contribución en materia de identificación, sistematización y difusión de dichas experiencias.

Finalmente, un campo en el que se puede empezar a reconciliar al Estado con la sociedad civil, es el de las políticas públicas, por ello conviene insistir en que si se logra reorientar e imbuir a la política social de una clara disposición autogestionaria, que estimule la formación de poderes $y$ fuerzas locales $y$ regionales, al tiempo que se depura de sus anacrónicos contenidos asistencialistas y clientelistas, puede adquirir un soporte masivo ascendente desde la base por los resultados que genere, de tal manera que impulse, ajuste y reoriente el sistema educativo y otros servicios del Estado, al ponerlos en concordancia con los procesos de empoderamiento organizacional de las comunidades rurales y urbanas.

\section{REFERENCIAS}

Andersson, G y Richards, H. (2015). Unbonded Organizing in Community. World Dignity University Press.

Bertheau, L. (2010). Encadenamientos productivos promovidos por el Hotel Punta Islita, en la comunidad de Islita, Nandayure, Guanacaste: 19942017. [Tesis de Licenciatura]. Escuela de Planificación y Promoción Social, Universidad Nacional, Costa Rica.

Burchet, W. (1969). El triunfo de Vietnam. Ediciones ERA.

Cadena, F. (2005) (Coordinador). De la economía popular a la economía desolidaridad. Itinerario de una búsqueda estratégica y metodológica para otro mundo posible. El Colegio de Tlaxcala.

Carmen, R. y Sobrado, M. (2004). Un futuro para los excluidos. Editorial de la Universidad Nacional.

Durston, J. (2000). ¿Qué es el capital social comunitario? Serie Politicas Sociales 38. Comisión Económica para América Latina.

Fanon, F. (1963). Los condenados de la tierra. Fondo de Cultura Económica.

Fukuyama, F. (2016). Los orígenes del orden político.Deusto.

Kapuscinski, R. (1989). El Emperador. Anagrama.

Kapuscinski, R. (2000). Ébano. Anagrama.

Langa, M. (2015). A follow-up report on the community work programme in Bokfontein. Centre for the Study of Violence and Reconciliaton, Wits University.

Leontiev, A. (1981). Actividad, conciencia y personalidad. Editorial Pueblo y Educación.

O`Donnel, G. (1997). Contrapuntos. Ensayos escogidos sobre autoritarismo y democratización. Paidós.

Organización Internacional del Trabajo (2002). $R$ 193: Recomendación sobre la promoción de las cooperativas, 2002. http://www.aciamericas.coop/IMG/recomendación193.pdf 
Ortiz, J. (2001). Epopeya Ramonense: parte de la Odisea de San Ramón. Editorial de la Universidad Nacional.

Putnam, R., Leonardi, R. y Nanetti, R. (1994). Para que la democracia funcione: Galac.

Roth, W. M. y Lee, Y. J. (2007). Vigotsky's neglected legacy: Cultural historical activity theory. Review of Educational Research, 77 (2), 186-232.

Sobrado, M. y Rojas, J. (2006). América Latina: Crisis del Estado clientelista y la construcción de Repúblicas Ciudadanas. Editorial de la Universidad Nacional.

Trocello, G. (2008). La manufactura de ciudadanos ciervos. Cultura politica y regímenes neopatrimonialistas. Nueva Editorial
Universitaria-Universidad Nacional de San Luis.

Valenzuela, J. (1998). El color de las sombras: chicanos, identidad y racismo. Plaza y Valdés.

Vygotsky, L. (1978). Mind in society: The development of higher psychological processes. Harvard University Press.

Vygotsky, L. (1995). Pensamiento y Lenguaje. Paidós.

Xiaobo, W. (2010). La China Emergente. China Press.
Fecha de ingreso: 29/10/2019

Fecha de aprobación: 30/03/2020 